\title{
Stord Orographic Precipitation Experiment (STOPEX): an overview of phase I
}

\author{
J. Reuder ${ }^{1}$, G. O. Fagerlid ${ }^{1}$, I. Barstad ${ }^{2}$, and A. Sandvik ${ }^{2}$ \\ ${ }^{1}$ Geophysical Institute, University of Bergen, Norway \\ ${ }^{2}$ Bjerknes Centre for Climate Research, Bergen, Norway
}

Received: 31 July 2006 - Revised: 9 January 2007 - Accepted: 15 February 2007 - Published: 26 April 2007

\begin{abstract}
STOPEX (Stord Orographic Precipitation Experiment) is a research project of the Geophysical Institute, University of Bergen, Norway, dedicated to the investigation of orographic effects on fine scale precipitation patterns by a combination of numerical modelling and tailored measurement campaigns. Between 24 September and 16 November 2005 the first field campaign STOPEX I has been performed at and around the island of Stord at the west coast of Norway, about $50 \mathrm{~km}$ south of Bergen. 12 rain gauges and 3 autonomous weather stations have been installed to measure the variability of precipitation and the corresponding meteorological conditions. This paper gives an overview of the projects motivation, a description of the campaign and a presentation of the precipitation measurements performed. In addition, the extreme precipitation event around 14 November with precipitation amounts up to $240 \mathrm{~mm}$ in less than $24 \mathrm{~h}$, is described and briefly discussed. In this context preliminary results of corresponding MM5 simulations are presented, that indicate the problems as well as potential improvement strategies with respect to modelling of fine scale orographic precipitation.
\end{abstract}

\section{Introduction}

As moist air is forced over mountains, orographic precipitation (OP) is formed (e.g. Smith, 1979; Jiang, 2003). The phenomenon has miscellaneous and partly grave implications on the environment. Eroded landscapes and fresh water supply are two examples of environmental impact by OP. Hazardous events such as mudslides, avalanches and flooding, killing numerous of people every year, are strongly related to OP. In the climate system, the phenomenon is essential in maintenance and development of glaciers and the balance of fresh water, as well as for long-term trends in terrain evolution and the variation of plant and animal life.

The main mechanism of OP is the terrain induced forced lifting of air masses. The resulting horizontal precipitation pattern depends critically on various atmospheric parameters, as the speed and direction of the flow towards the mountain, the available moisture, and the stability of the approaching air. In addition the shape and dimension of the orographic barrier plays an important role. The spillover effect (e.g. Sinclair et al., 1996), i.e. the transport of rain droplets mainly created in the upwind lifting and condensation region into the lee in the presence of strong winds, is an integral manifestation of all parameters mentioned above. Combining flow dynamics, thermodynamics and cloud microphysics, this phenomenon provides a challenging test for model parameterization schemes. Recent studies (e.g. Zängl, 2005; Colle, 2004; Roe and Baker, 2005) have mainly focussed on modelling of OP associated to a typical halfwidth of the mountain barrier of 20 to $50 \mathrm{~km}$. In the paper presented here we will emphasize to a somewhat smaller scale in the order of 5 to $10 \mathrm{~km}$.

Norway (Fig. 1) with its steep mountains located in the belt of extra-tropical cyclone bringing moisture from lower latitudes, is an ideal test area for OP's impact. Due to its exposure to open ocean and the high frequency of extratropical cyclones approaching the area, in particular the western coast provides an excellent opportunity to study OP with high probability of detection.

We will present an overview of the measurements performed during the campaign STOPEX I. This campaign is intended to improve our understanding in fine scale orographic precipitation patterns by combination of model simulations and analysis of measurements.

Correspondence to: J. Reuder

(joachim.reuder@gfi.uib.no)

Published by Copernicus GmbH on behalf of the European Geosciences Union. 


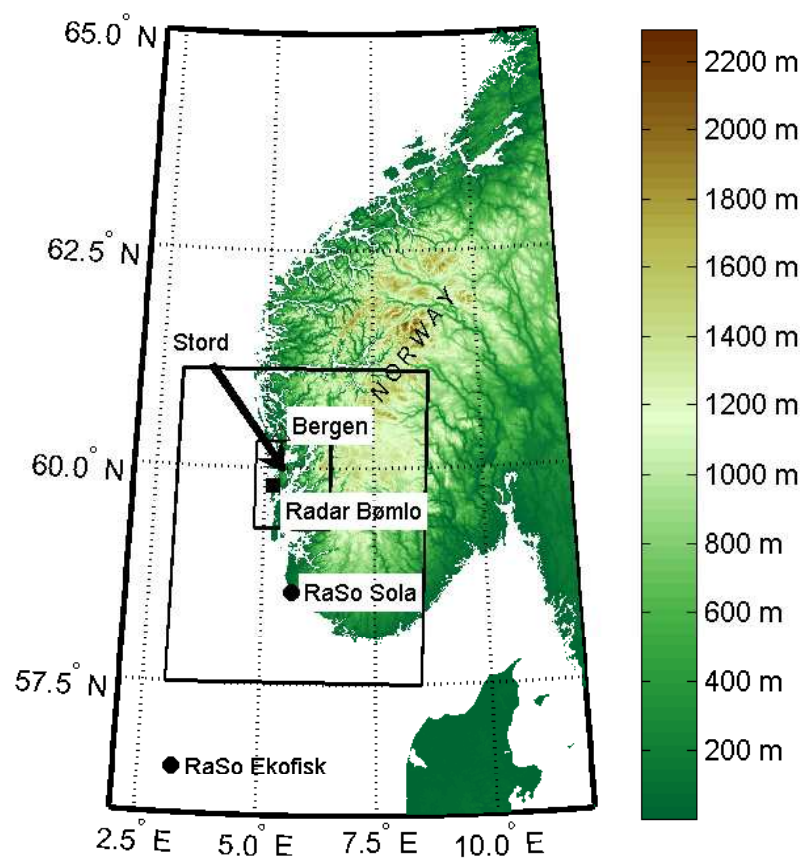

Fig. 1. Topography of Southern Norway. The two boxes represent the two innermost domains (D3, D4) used for MM5 model simulations. In addition the locations of the precipitation radar at Bømlo and the two nearest upstream radiosonde stations Sola and Ekofisk are displayed.

\section{Campaign STOPEX I}

\subsection{Motivation}

The island of Stord, located to the south of the city Bergen at the west coast of Norway, has been the focus area for the campaign (Fig. 2). The island extends about $30 \mathrm{~km}$ northsouth and $10 \mathrm{~km}$ east-west and its highest mountains form a plateau at around $600 \mathrm{~m}$. Climatological recordings of precipitation on the windward and the leeward side of the island indicate a large horizontal gradient that has to be associated with orographic effects. On the eastern, predominantly leeward side, Børtveit shows an annual average of $2661 \mathrm{~mm}$ during the 1931-1960 climatological period, while Fitjar $10 \mathrm{~km}$ further upstream merely reaches a mean value of $1590 \mathrm{~mm}$ per year.

The theoretical work of Smith and Barstad (2004) and the corresponding observational assessment (Barstad and Smith, 2005) have been the initial motivation of this field campaign. Observations from existing campaigns do not give a clear view of how well the theory works. Particularly, information on the natural time scale of OP related processes is needed. The formation of hydrometeors in OP depends on the time the droplets stay in an environment favorable for condensational growth, mainly in the windward lifting zone. Advection can transport these droplets to evaporation zones, partic-
Table 1. List of rain gauges (P1-P12) and weather stations (AWS1AWS3) during STOPEX I.

\begin{tabular}{llccc}
\hline name & $\begin{array}{c}\text { latitude } \\
\text { deg N }\end{array}$ & $\begin{array}{c}\text { longitude } \\
\text { deg E }\end{array}$ & $\begin{array}{c}\text { altitude } \\
{[\mathrm{m}]}\end{array}$ \\
\hline P1 & Korsvik & 59.868 & 5.295 & 33 \\
P2 & Hovåsen & 59.860 & 5.369 & 177 \\
P3 & Ytste Sørlivatnet & 59.867 & 5.407 & 242 \\
P4 & Store Tjødnadalen & 59.874 & 5.454 & 551 \\
P5 & Stemmetjødno & 59.880 & 5.464 & 504 \\
P6 & Utløp Strupen & 59.890 & 5.484 & 338 \\
P7 & Børtveitdalen & 59.896 & 5.490 & 282 \\
P8 & Børtveit & 59.889 & 5.520 & 10 \\
P9 & Nord-Huglo & 59.864 & 5.570 & 32 \\
P10 & Lundastølen & 59.843 & 5.480 & 187 \\
P11 & Kattnakkjen & 59.875 & 5.494 & 697 \\
P12 & Vistvik & 59.944 & 5.413 & 104 \\
\hline AWS1 & Nautøy & 59.737 & 5.386 & 2 \\
AWS2 & Kattnakkjen & 59.874 & 5.493 & 700 \\
AWS3 & Korsneset (Nord-Huglo) & 59.824 & 5.573 & 3 \\
\hline
\end{tabular}

ularly in the lee, where number and size of droplets will decrease. The observational indications from Stord have shown that this site is promising for studies of these mechanisms.

Guidance for the campaign design was provided by the theory, first of all by running a linear model in a quasi-steady operational modus for 3 months upfront of the campaign. It was decided to deploy rain gauges ("tipping-buckets") where the theory indicated the strongest gradients, and see if the gradient changed dramatically for different weather regimes. The gauges have been aligned across and along the highest mountains (P1-P12 in Fig. 2). The gauge at P2 failed after short operation, therefore only 11 precipitation data series are available for evaluation. At one location, three collectors $(\mathrm{P} 4$, P5, P6) have been located within a distance below $2 \mathrm{~km}$ at comparable elevation to test if the collectors capture the same precipitation signal. In addition three autonomous weather stations (AWS1-AWS3) recording $10 \mathrm{~min}$ averages of wind, temperature and humidity have been deployed. They were partly used to see if channelling effects around the island could explain some of the variation in precipitation. Their location is also indicated in Fig. 2.

\subsection{Instrumentation}

For the precipitation measurements the data logging rain gauge HOBO RG2 has been used. The instruments are based on the tipping bucket principle and enable a resolution of $0.2 \mathrm{~mm}$. The rain gauges have been validated by a three month intercomparison campaign from May to August 2005. For that two of the 12 HOBO rain gauges (serial numbers 20371 and 20372) have been operated in parallel to the official precipitation registration performed by the Norwegian Meteorological Service (met.no) at the station BergenFlorida based on standard rain gauge measurements. 
The monthly integrated precipitation amount of both HOBO instruments coincides within $\pm 0.5 \%$. Compared to the measurements of met.no the RG2 gauges underestimate monthly integrated precipitation slightly by $2 \%$ (June) to $6 \%$ (May). A closer look into daily integrated values shows that the underestimation mainly occurs for small precipitation amounts below $5 \mathrm{~mm} /$ day. This behavior can most likely be addressed to the protective grating of the HOBO instrument. It is intended to minimize blocking of the rain gauge by e.g. falling leaves or insects. Of course it also provides an additional surface area that increases losses in measured precipitation by the effects of surface wetting and evaporation. These effects are strongest for weak and intermittent precipitation events.

The meteorological measurements at the three selected sites have been performed by autonomous weather stations (AWS) of Aanderaa Data Instruments (AADI). Each of the stations has been equipped with sensors for temperature, relative humidity, wind speed, and wind direction.

\subsection{Measurements}

The measurements of STOPEX I cover the time period between 24 September and 16 November 2005. During the campaign, 21 different precipitation events have been identified with respect to the large scale synoptic situation, derived from surface and $500 \mathrm{hPa}$ analysis charts and infrared satellite images. An overview is given in Table 2. For each identified period the table provides a short description of the synoptic situation, the range of observed accumulated precipitation at the stations P1 to P12, and the average surface temperature measured at the AWS3 Huglo-Korsneset. From radiosonde ascents at Sola, about $150 \mathrm{~km}$ south of Stord, wind speed and wind direction at the $925 \mathrm{hPa}$ level have been used to characterize the large scale flow conditions. The soundings available every $12 \mathrm{~h}$ have been selected with respect to best representation of the period of maximum precipitation during each event. In addition two stability parameters $N_{d}$ and $N_{m}$ for the atmospheric boundary layer have been calculated from the sounding data at the surface and the $850 \mathrm{hPa}$ level:

$$
N_{d}=\delta \sqrt{\left|\frac{g_{0}}{\theta} \frac{d \theta}{d z}\right|} \quad N_{m}=\delta \sqrt{\left|\frac{g_{0}}{\theta_{e}} \frac{d \theta_{e}}{d z}\right|}
$$

$g_{0}:$ gravity

$\theta:$ potential temperature

$\theta_{e}:$ equivalent potential temperature

$z:$ altitude

$\delta:$ stability indicator $(+1:$ stable; -1 : instable)

$N$ basically represents a slightly modified version of the Brunt-Vaisala frequency for dry- and moist-adiabatic conditions, with negative values (instead of imaginary numbers) indicating instability. The magnitude of both stability parameters or a combination of them are expected to provide a

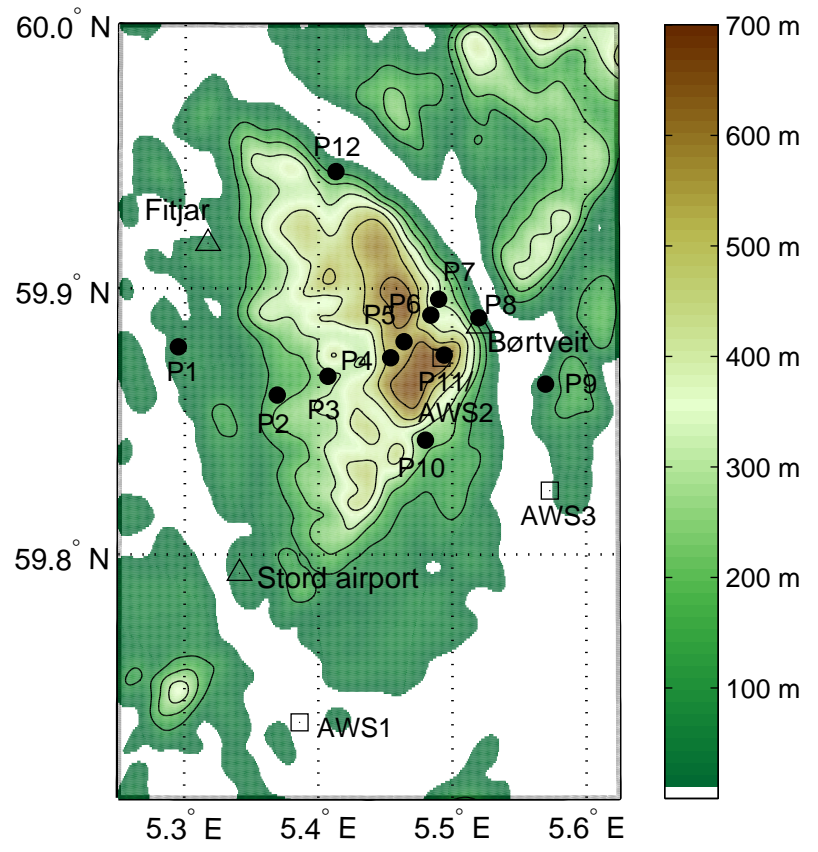

Fig. 2. Topography of Stord with location of rain gauges (P1P12) and autonomous weather stations (AWS1-AWS3) during the field campaign STOPEX I. At Stord airport continuous routine observations are performed by the Norwegian Meteorological Service met.no.

measure for the classification of the identified precipitation events into stratiform, convective and mixed cases.

During the 8 week campaign a total amount of precipitation between $340 \mathrm{~mm}$ (P1: Korsvik, $30 \mathrm{~m}$ a.s.1.) and 1237 mm (P11: Kattnakkjen, 697 m a.s.l.) has been observed (Fig. 3). It has to be mentioned that these precipitation values have not been corrected with respect to the known decrease in sample efficiency with increasing wind speed (e.g. WMO, 1998; Nespor and Sevruk, 1999). Due to the measurement height of around $1 \mathrm{~m}$ above ground, and the shielded surrounding of some of the rain gauges, the wind effects should not be too dramatic, but they will tend to increase the measured values especially for the higher and therefore more wind exposed sites.

Figure 4 shows that the precipitation in general increases markedly with altitude. In addition the data indicate that the stations on the leeward side of Stord (P6 to P9) receive distinctly higher precipitation amounts then those at corresponding altitudes on the windward side. P6 and P7, located around $300 \mathrm{~m}$, reach values comparable to $\mathrm{P} 4$ and $\mathrm{P} 5$, elevated above $500 \mathrm{~m}$ on the windward side of the mountains. Compared to the westernmost site P1 close to sea level, the two leeward measurements at comparable elevation (P8, P9) registered more than twice in total amount of precipitation. This feature is a typical manifestation of the spillover effect. 
Table 2. Overview of precipitation events during STOPEX I. Values given for each period are the range of accumulated precipitation $(P)$ measured by the rain gauges, the $925 \mathrm{hPa}$ wind speed and wind direction from sounding at Sola, the stability as modified (negative values indicate instable conditions) Brunt-Vaisala frequencies $\left(N_{d}\right.$ and $\left.N_{m}\right)$ calculated from potential temperature $\theta$ and equivalent potential temperature $\theta_{e}$ between surface and $850 \mathrm{hPa}$, and the average temperature $\left(T_{0}\right)$ measured at Huglo-Korsneset. The soundings available every $12 \mathrm{~h}$ have been selected with respect to be representative for the period of maximum amount of precipitation during each event.

\begin{tabular}{|c|c|c|c|c|c|c|c|}
\hline \# & time interval & synoptic situation & $\begin{array}{c}\mathrm{P} \\
{[\mathrm{mm}]}\end{array}$ & $\begin{array}{c}\mathrm{vv} \\
{\left[\mathrm{m} \mathrm{s}^{-1}\right]}\end{array}$ & dir & $\begin{array}{c}N_{d} / N_{m} \\
{\left[\times 10^{-2} s^{-1}\right]}\end{array}$ & $\begin{array}{c}T_{0} \\
{[\operatorname{degC}]}\end{array}$ \\
\hline 1 & 27.09. 00-28.09. 12 & cold front and showers behind & $11-48$ & 24 & $\mathrm{~S}$ & $1.25 /-1.35$ & 13 \\
\hline 2 & 28.09. 12-30.09. 00 & several occlusions & $20-42$ & 9 & SW & $0.93 /-0.50$ & 10 \\
\hline 3 & 30.09. 09-02.10. 03 & frontal system & $14-81$ & 18 & $\mathrm{~S}$ & $1.03 /-0.30$ & 13 \\
\hline 4 & 02.10. 09-04.10. 03 & occlusion & $7-39$ & 4 & $\mathrm{~W}$ & $0.88 /-0.75$ & 11 \\
\hline 5 & 08.10. 18-09.10. 18 & sharp cold front with few subsequent showers & $20-37$ & 21 & SSE & $1.45 / 0.74$ & 10 \\
\hline 6 & 12.10. $18-14.10 .12$ & cold front and subsequent showers & $17-60$ & 23 & SSE & $1.25 /-0.60$ & 13 \\
\hline 7 & 20.10. 00-23.10. 00 & several fronts/occlusions; rather complicated situation & $35-115$ & 11 & SSW & $0.70 /-1.08$ & 11 \\
\hline 8 & 25.10. 00-27.10. 00 & occlusion and warm front, close to center of low & $14-60$ & 30 & SE & $1.47 / 1.34$ & 6 \\
\hline 9 & 28.10. 12-29.10. 00 & cold front & $12-33$ & 28 & $\mathrm{~S}$ & $1.28 / 0.12$ & 13 \\
\hline 10 & 30.10. 09-31.10. 06 & cold front & $3-28$ & 20 & $\mathrm{~S}$ & $1.32 / 0.85$ & 14 \\
\hline 11 & 31.10. 15-01.11. 06 & cyclogenesis at stationary front & $8-20$ & 21 & SSE & $1.33 / 0.94$ & 12 \\
\hline 12 & 30.10. 09-31.10. 06 & passage of cold front and 2 subsequent troughs & $5-32$ & 15 & S & $1.10 /-0.33$ & 11 \\
\hline 13 & $02.11 .12-04.11 .00$ & occlusion and subsequent trough & $14-56$ & 19 & SSE & $1.46 / 1.13$ & 12 \\
\hline 14 & 04.11. 00-05.11. 00 & occlusion & $18-84$ & 14 & S & $1.36 / 0.90$ & 12 \\
\hline 15 & 05.11. 12-06.11. 09 & occlusion & $1-17$ & 10 & SSW & $1.17 / 0.41$ & 10 \\
\hline 16 & $06.11 .12-08.11 .00$ & warm front, cold front, trough & $8-48$ & 18 & SSW & $1.52 / 1.21$ & 11 \\
\hline 17 & 08.11. 00-09.11. 18 & passage of frontal system, cyclogenesis & $43-86$ & 25 & SSW & $1.12 / 0.02$ & 13 \\
\hline 18 & 10.11. 00-11.11. 06 & occlusion and subsequent showers & $15-44$ & - & - & - & 10 \\
\hline 19 & 11.11. 03-12.11. 03 & passage of warm and cold front & $3-26$ & 13 & $\mathrm{~S}$ & $1.20 / 0.71$ & 11 \\
\hline 20 & 12.11. 03-13.11. 12 & occlusion, cyclogenesis & $8-53$ & 14 & W & $0.96 /-0.49$ & 10 \\
\hline 21 & 13.11. 21-15.11. 15 & passage of frontal system, subsequent showers & $45-240$ & $14-25$ & SW-W & $1.18 / 0.76$ & 10 \\
\hline
\end{tabular}

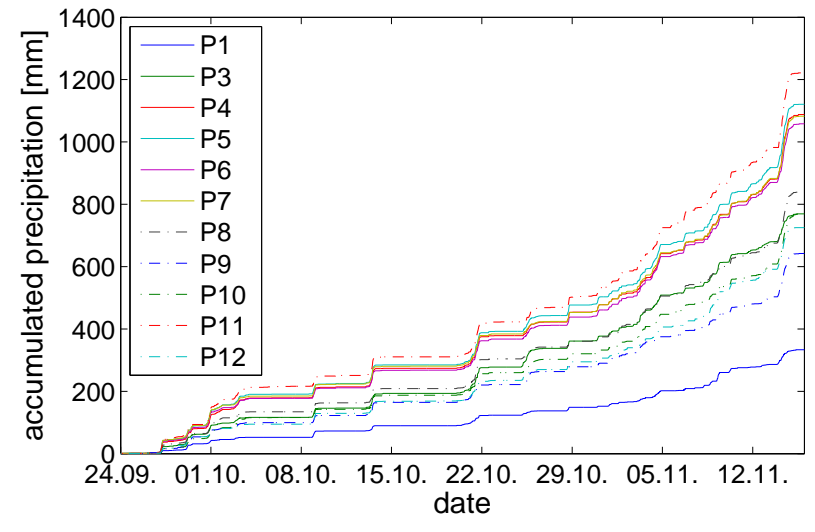

Fig. 3. Accumulated precipitation during the 8 week campaign of STOPEX I.

\section{Case study: Extreme precipitation event 13-15 November 2005}

During 14 November the fronts of a low pressure system pass southern Norway and lead to exceptionally high precipitation amounts along the Norwegian coast. On 12 November 00:00 UTC, the cyclone is already well developed and

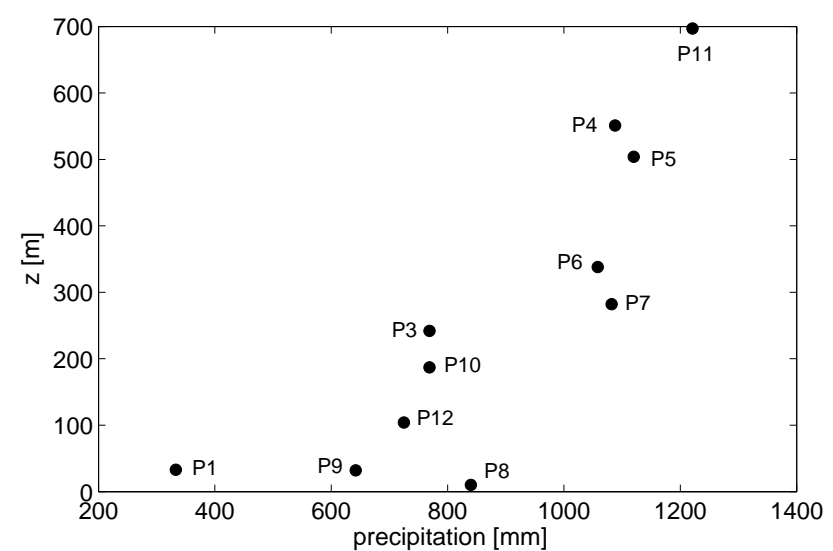

Fig. 4. Altitude dependence of accumulated precipitation during the 8 week campaign of STOPEX I.

its center $(986 \mathrm{hPa})$ is located around $60^{\circ} \mathrm{N}$ at the east coast of Newfoundland. Between it and a strong anticyclone over the central North Atlantic, subtropical moist air is transported towards North. Until 13 November 00:00 UTC the cyclone has slightly weakened $(1001 \mathrm{hPa})$ and moved in between Greenland and Iceland. During the next $24 \mathrm{~h}$ the system is 


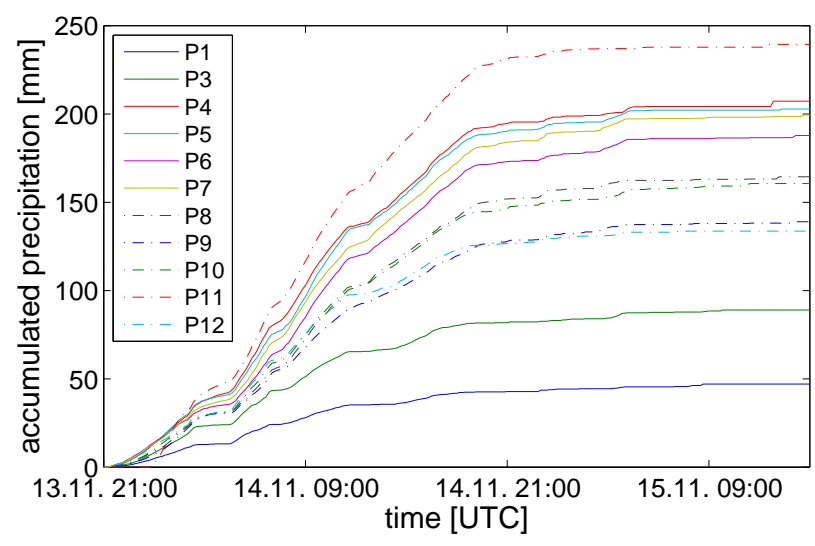

Fig. 5. Accumulated precipitation during event 21 of STOPEX I. For extended legend see Fig. 3.

intensifying vigorously (14 November 00:00 UTC: $976 \mathrm{hPa}$ ), steadily advecting moist subtropical air.

\subsection{Measurements}

The precipitation field associated with this frontal system reaches Stord on 13 November around 22:00 UTC (Fig. 5). Within a $24 \mathrm{~h}$ period, precipitation amounts between $45 \mathrm{~mm}$ (P1: Korsvik) and $240 \mathrm{~mm}$ (P11: Kattnakkjen) are measured by the STOPEX rain gauge network. A closer look into the time series of accumulated precipitation reveals four distinct periods of high, nearly constant precipitation intensity, indicated by nearly linear and steep increase in accumulated precipitation. These intense precipitation periods, typically lasting 3 to $5 \mathrm{~h}$ are separated by shorter (lasting typically $1-$ $2 \mathrm{~h}$ ) phases of distinctly lower precipitation intensities. This temporal structure is occurring nearly simultaneously at all rain gauges and can therefore not be related to local orography. Explanation for these fluctuations must therefore rather be connected to large scale fluctuations.

Figure 6 presents the altitude dependence of the accumulated precipitation during event 21 from 13.11.2005 21:00 UTC until 15.11.2005 15:00 UTC. This event was characterized by quite strong wind (10 min averages measured at AWS3: $15-25 \mathrm{~m} / \mathrm{s}$ ), at the beginning from Southwest, later from West. The selected positions of rain gauges oriented along the mean incoming flow of moist air (except P10 and P12) provide therefore an ideal transect for the investigation of this precipitation event. The measured precipitation amounts show again a distinct increase with altitude. By separating windward (P1-P5) and leeward stations (P6$\mathrm{P9}$ ), two different regimes of altitude dependence of the precipitation amount become evident. Obviously both regimes can be approximated by a linear dependency with height indicated by the fitted curves in Fig. 6 . The distinctly larger gradients are observed windward, with an increase of nearly

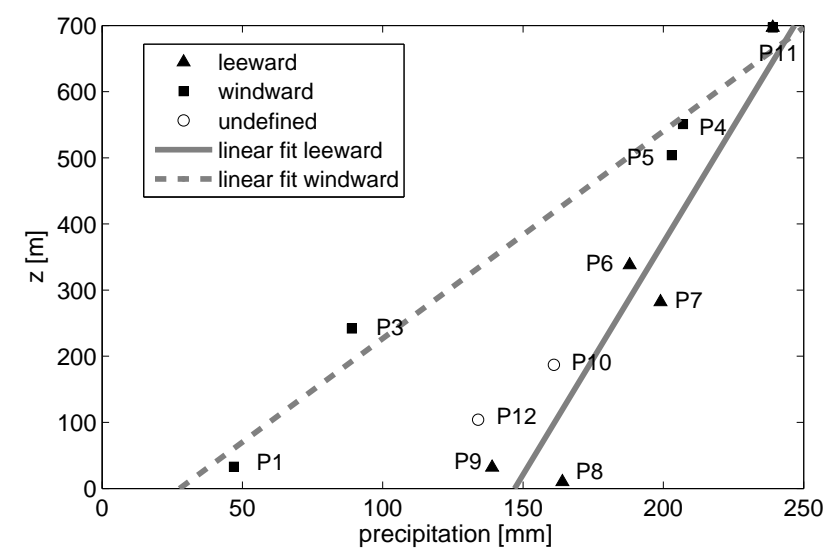

Fig. 6. Altitude dependence of accumulated precipitation during event 21 of STOPEX I.

$200 \mathrm{~mm}$ per $700 \mathrm{~m}$, i.e. nearly fourfold precipitation amount at P11 compared to P1. The fit through the data of the leeward stations results in an increase of around $100 \mathrm{~mm}$ per $700 \mathrm{~m}$ (from appr. 150 to $250 \mathrm{~mm}$ ). The leeward stations close to sea level receive around $150 \mathrm{~mm}$ about, i.e. approximately the threefold precipitation amount of P1 upstream. This again can only be explained by the spillover effect already mentioned above.

\subsection{Model simulations}

In a first attempt, numerical sensitivity experiments for the event 21 have been performed with the mesoscale atmospheric model MM5 version 3.6 (see Dudhia, 1993; Grell et al., 1994, or http://www.mmm.ucar.edu/mm5/ for details). The model has been configured with four domains, the outermost covering the southern part of Norway, the North Sea and parts of the Norwegian Sea, the innermost covering the island of Stord and its surroundings. The two inner domains D3 and D4 are shown as boxes in Fig. 1. The horizontal grid resolutions have been selected as $27,9,3$ and $1 \mathrm{~km}$, the corresponding modelling time steps are 81, 27, 9 and $3 \mathrm{~s}$. Each numerical simulation started on November, 13:00 at 12:00 UTC and lasted for $30 \mathrm{~h}$. The model has been initialized with analyzes of upper air and surface data from ECMWF, and lateral boundary values have been included every $6 \mathrm{~h}$ during the simulation. Model output data for further analysis have been taken every hour.

Sensitivity experiments with 5 different microphysical parameterizations schemes given in Table 3 have been performed. The radiation transfer has been treated by the Dudhia radiation scheme (Dudhia, 1993). The Grell convection parameterization (Grell et al., 1994) has been used for the $27 \mathrm{~km}$ domain, while convection is assumed to be solved explicitly for the higher horizontal resolutions. Turbulence is parameterized by the MRF scheme (Hong and Pan, 1996). 
Table 3. Microphysical parameterization schemes used for MM5 simulations.

\begin{tabular}{cll}
\hline abbreviation & scheme & reference \\
\hline MP4 & simple ice & Dudhia (1993) \\
MP5 & Reisner 1 microphysics & Reisner et al. (1998) \\
MP6 & Goddard microphysics & Lin et al. (1983), Tao et al. (1989), Tao and Simpson (1993) \\
MP7 & Reisner 2 microphysics & Reisner et al. (1998), Thompson et al. (2004) \\
MP8 & Schultz microphysics & Schultz (1995)
\end{tabular}

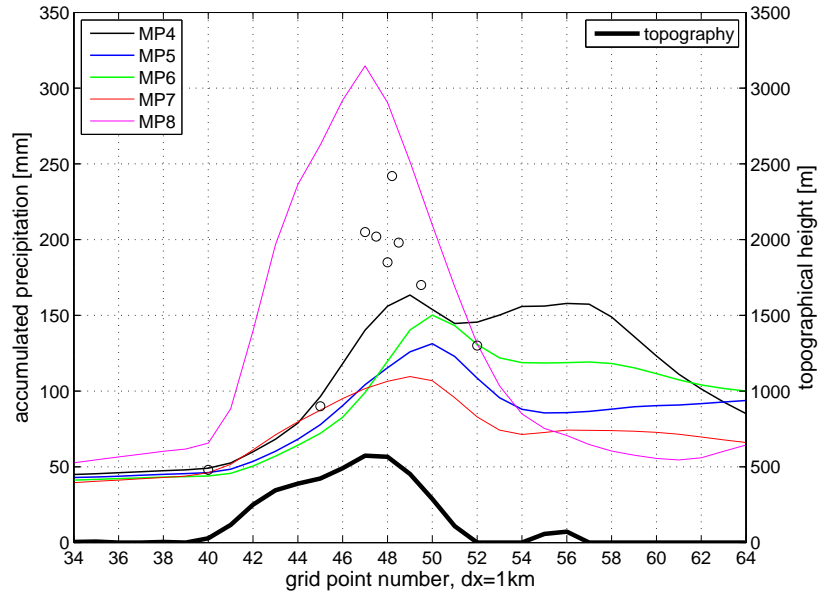

Fig. 7. MM5 simulations of accumulated precipitation along a transect across Stord for the period 13 September 12:00 UTC until 14 September 18:00 UTC using five different cloud microphysics parameterization schemes. The bold solid line represents the MM5 model topography. Circles denote corresponding observations of the rain gauge network.

The results of the model simulations along a transect across Stord are presented in Fig. 7. Except the Schultz microphysics scheme MP8 the MM5 results agree reasonable for the windward side of Stord. Approaching the highest part of the mountains, the deviations between these schemes increase. The maxima of predicted precipitation are slightly shifted to the lee and range between $125 \mathrm{~mm}$ and $165 \mathrm{~mm}$ for the simulated $30 \mathrm{~h}$ period. Further downstream the differences between the different schemes reach a maximum (MP4: $160 \mathrm{~mm}$; MP 7: $75 \mathrm{~mm}$ ) before obviously converging again about $15 \mathrm{~km}$ downstream the top of the orography. In contrast the Schultz scheme MP8 shows a completely different behavior. It already starts with slightly enhanced precipitation when approaching the island. Reaching the coast line the amount of precipitation increases sharply to a maximum of more than $310 \mathrm{~mm}$ that is allocated exactly above the highest topography. In the lee the accumulated precipitation decreases with distance nearly as steep as it increased upstream.
The occurring differences in total precipitation amount and in the spatial distribution amongst the model runs confirm the need of appropriate precipitation measurements for validation purposes. Measured accumulated precipitation values for the event 21 from the rain gauges $\mathrm{P} 1$ to $\mathrm{P} 9$, located close to the transect, have been plotted as open circles in Fig. 7. Excellent agreement between measurements and MP4 to MP7 simulations can be found at the windward side of Stord. In contrast to the results of these simulations the measured maximum of precipitation coincides with the maximum of topography. Moreover the measured values are markedly above the simulated ones at these elevations. Due to the fact that the measurements have not been corrected with respect to wind-induced undersampling, the real measured values should tend to be even higher. In the lee of the island measurements and model results seem to converge again. Based only on one measurement, this fact should not be overinterpreted. Anyway, the model simulations point out that for future validation purposes additional rain gauges have to be deployed in the downstream region.

\section{Summary and Outlook}

During STOPEX I high resolution time series of precipitation have been derived from rain gauge measurements at 11 sites on and around the island of Stord. These measurements represent an unique data set on horizontal fine-scale variability of OP. The data presented here preliminarily, will be used in the future for extended comparison and validation tasks of OP model simulations both using advanced weather prediction models (e.g. MM5) as well as simpler process oriented models, like the linear model of OP proposed by Smith and Barstad (2004). Due to its high temporal resolution the presented data set can not only be used for comparing daily amounts of precipitation, as mostly done in the past. These data now enable moreover the validation of simulated precipitation intensities and have thus a large potential to increase our understanding of the underlying microphysical processes.

In addition this first campaign has given invaluable information for the redistribution and extension of the rain gauge network for the forthcoming, extended campaign STOPEX II 
during autumn 2006. At least 6 additional rain gauges will be deployed and a recently purchased Micro Rain Radar (MRR by Metek) will be available both for stationary and mobile precipitation measurements. Additional sources of information (e.g. integrated water vapor from dual band GPS measurements (e.g. Bevis et al., 1992) and high resolution precipitation information derived from the mobile phone transmitter network (Messer et al., 2006) will complement our own measurements during STOPEX I and STOPEX II.

Acknowledgements. The authors thank their colleague Tor de Lange for his support in preparation and field setup of instrumentation and in data acquisition and handling. The rain gauges used in this project have been funded by a grant of Meltzer foundation. We are also grateful to the reviewers for their helpful and constructive suggestions and comments.

Edited by: S. C. Michaelides and E. Amitai

Reviewed by: anonymous referees

\section{References}

Barstad, I. and Smith, R. B.: Evaluation of an orographic precipitation model, J. Hydrometeorol., 6, 85-99, 2005.

Bevis, B. G., Bussinger, S., Herring, T. A., Rocken, C., Anthes, R. A., and Ware, R. H.: GPS meteorology: Remote sensing of atmospheric water vapor using the Global Positioning System, J. Geophys. Res., 97, 15 787-15 801, 1992.

Colle, B. A.: Sensitivity of orographic precipitation to changing ambient conditions and terrain geometries: An idealized modeling perspective, J. Atmos. Sci., 61, 588-606, 2004.

Dudhia, J.: A nonhydrostatic version of the Penn State NCAR Mesoscale Model - Validation tests and simulation of an Atlantic cyclone and cold-front, Mon. Wea. Rev., 121, 1493-1513, 1993.

Grell, G., Dudhia, J., and Stauffer, D.: A Description of the FifthGeneration Penn State/NCAR Mesoscale Model (MM5), National Centre for Atmospheric Research, Boulder Colorado, US, 1994.

Hong, S.-Y. and Pan, H.-L.: Non-local boundary layer vertical diffusion in a medium-range forecast model, Mon. Wea. Rev., 124, 2322-2339, 1996.

Jiang, Q.: Moist dynamics and orographic precipitation, Tellus, 55A, 301-316, 2003.
Lin, Y.-L., Farley, R. D., and Orville, H. D.: Bulk parameterization of the snow field in a cloud model, J. Clim. Appl. Meteorol., 22, 1065-1092, 1983.

Messer, H., Zinevich, A., and Alpert, P.: Environmental monitoring by wireless communication networks, Science, 312, 713, 2006.

Nespor, V. and Sevruk, B.: Estimation of wind-induced error of rainfall gauge measurements using a numerical simulation, J. Atmos. Ocean. Tech., 16, 450-464, 1999.

Reisner, J., Rasmussen, R. M., and Bruintjes, R. T.: Explicit forecasting of supercooled liquid water in winter storms using the MM5 mesoscale model, Q. J. R. Meteorol. Soc., 124, 10711107, 1998.

Roe, G. H. and Baker, M. B.: Microphysical and geometrical controls on the pattern of orographic precipitation, J. Atmos. Sci., 63, 861-880, 2005.

Schultz, P.: An explicit cloud physics parameterization for operational numerical weather prediction, Mon. Wea. Rev., 123, 33313343, 1995.

Sinclair, M. R., Wratt, D. S., Henderson, R. D., and Gray, W. R.: Factors affecting the distribution and spillover of precipitation in the Southern Alps of New Zealand - A case study, J. Appl. Meteorol., 36, 428-442, 1996.

Smith, R. B.: The influence of mountains on the atmosphere, Adv. Geophys., 21, 87-230, 1979.

Smith, R. B.: A linear time-delay model of orographic precipitation, J. Hydrol., 282, 2-9, 2004.

Smith, R. B. and Barstad, I.: A linear theory of orographic precipitation, J. Atmos. Sci., 61, 1377-1391, 2004.

Tao, W.-K., Simpson, J., and McCumber, M.: Ice-water saturation adjustment, Mon. Wea. Rev., 117, 231-235, 1989.

Tao, W.-K. and Simpson, J.: Goddard Cumulus Ensemble Model. Part I: Model description, Terr. Atmos. Ocean. Sci., 4, 192-209, 1993.

Thompson, G., Rasmussen, R. M., and Manning, K.: Explicit forecasts of winter precipitation using an improved bulk microphysics scheme. Part I: Description and sensitivity analysis, Mon. Wea. Rev., 132, 519-542, 2004.

WMO: WMO Solid Precipitation Measurement Intercomparison, WMO Instruments and Observing Methods, Report No. 67, WMO/TD 872, 1998.

Zängl, G.: The impact of lee-side stratification on the spatial distribution of orographic precipitation, Q. J. R. Meteorol. Soc., 131, 1075-1091, 2005. 